\title{
SITUACIÓN DEL INDÍGENA AMAZÓNICO PERUANO: A MITAD DE UNA DOBLE E IRRECONCILIABLE DISCURSIVIDAD?
}

\section{SITUAÇÃO DO INDÍGENA AMAZÔNICO PERUANO: NO MEIO DE UMA DUPLA E IRRECONCILIÁVEL DISCURSIVIDADE?}

\author{
Jesús José Diez Canseco Carranza ${ }^{1}$
}

\section{RESUMEN:}

A partir de las líneas metodológicas del análisis del discurso se analizará la novela El hablador de Mario Vargas Llosa. En esta narración, será remarcado el recorrido de dos voces antagónicas, de dos visiones superpuestas en torno a un mismo objeto: el Perú amazónico. Una voz es la del narrador, crítico del "atraso y arcaísmo" de los indígenas de la selva y la otra, la del mismo hablador, memoria viva de la cultura oral machiguenga. Tal confrontación evidencia las rupturas internas del estado-nación peruano y la coexistencia conflictiva de universos culturales heterogéneos. En este contexto, el mito del progreso occidental es invertido y permanece bajo las estructuras míticas amerindias. Con ello, se llega a la cuestión del papel del novelista latinoamericano moderno o de la problematización de la noción de escritor comprometido y de su contracara (un narrador de gran prestigio comunitario pero, que, en contextos mayores, sigue siendo una ilusión).

\section{PALABRAS-CLAVE:}

Ciudad letrada. Transculturación. Amazonía peruana. Oralidad.

\section{RESUMO:}

A partir das linhas metodológicas da análise do discurso será analisado o romance El hablador de Mario Vargas Llosa. Nesta narrativa, será remarcado o percurso de duas vozes antagônicas, de duas visões superpostas em torno de um mesmo objeto: o Peru amazônico. Uma voz é a do narrador, crítico do "atraso e arcaísmo" dos indígenas da floresta e a outra, a do mesmo falador, memória viva da cultura oral machiguenga. Tal confrontação evidencia as rupturas internas da naçãoestado peruana e a coexistência conflituosa de universos culturais heterogêneos. Neste contexto, o mito do progresso ocidental é invertido e fica sob as estruturas míticas ameríndias. Com isto, chega-se à questão do rol do romancista latinoamericano moderno ou da problematização da noção do escritor comprometido e da sua contrafaz (um narrador oral de grande prestígio comunitário, mas que, em contextos maiores, segue sendo uma ilusão).

\section{PALAVRAS-CHAVE:}

Cidade letrada. Transculturação. Amazônia peruana. Oralidade.

1 Graduado em Letras Modernas pela Universidad Nacional de Córdoba, UNC, Argentina, Mestrando em Letras: Linguagem e Identidade pela Universidade Federal do Acre, Bolsista Capes Demanda Social, Convênio Grupo Coimbra de Universidades Brasileiras (GCUB)/ Organização dos Estados Americanos (OEA), Programa de Alianças para a Educação e a Capacitação (Bolsas Brasil - PAEC OEA-GCUB). 
atinoamérica, como
refiere Walter Mignolo (2005, p.59) es, hoy, un lugar construido, una idea o narrativa "macro" gestada desde el siglo XIX y que engloba otras narrativas menores $y$ una serie de discursos. Sin embargo, Latinoamérica es, también, una región localizable, cartografiable, en la que conviven gentes, paisajes, microclimas y tiempos diversos (MIGNOLO, 2005, p. 59). Dentro de esta variedad es posible identificar un espacio de grandes dimensiones, compartido, simultáneamente, por varias naciones: la Amazonía. Este lugar, infinito y exuberante, se erige, hoy, como locus creado a partir de la confluencia y choque de diversos discursos (políticos, geográficos, antropológicos, ecológicos, históricos, literarios, etc.) y de la sumatoria de sinnúmero de narrativas (personales y colectivas, institucionales y autónomas).

Ese espacio natural, poblado desde los albores, es y fue escenario de hechos cuya naturaleza nos obliga a reflexionar en torno a la condición humana y sus claroscuros. En tal sentido, si retrocediéramos hasta los primeros años de la conquista de esos territorios, notaremos que la violencia ejercida, a través de distintas modalidades, no deja de sucederse. Igualmente, que las escisiones o fracturas existentes entre los grupos humanos allí asentados "gozan" aún de vigencia.

Es necesario destacar y cuestionar, entonces, los intentos de silenciar y aniquilar a quienes, luego de sufrir la ocupación de sus tierras, fueran vencidos y obligados a demoler sus soportes físicos, filosóficos y espirituales. Sobre los juicios de valor que, tras la conquista, las culturas originarias recibirían, Franz Fanon dice:

o indígena é declarado impermeávelà ética. Ausência de valores e também negação dos valores. Nesse sentido, ele é o mal absoluto. Elemento corrosivo, destruindo tudo de que se aproxima elemento deformante, desfigurando tudo o que se refere à estética ou à moral, depositário de forças maléficas, instrumento 
inconsciente e irrecuperável de forças cegas... (FANON, 2005, p. 58).

En este aspecto, categorías provenientes de los estudios literarios y culturales latinoamericanos como las de heterogeneidad básica y principio de alteridad, principalmente, cobran especial importancia. Esto remarca que América Latina y las regiones allí constituidas (Amazonía, Andes, Caribe, Patagonia, Mesoamérica, etc.) son espacios donde conviven -y no de manera armoniosa- distintos grupos humanos, cada cual víctima o patrocinador de distintas formas de violencia. Tratando de caracterizar a las sociedades andinas, Antonio Cornejo Polar define la heterogeneidad básica como:

...una categoría mediante la cual se trata de reivindicar la heteróclita pluralidad que define a la sociedad y cultura peruana, aislando regiones y estratos y poniendo énfasis en las abisales diferencias que separan y contraponen, hasta con beligerancia, a los varios universos socioculturales y a los muchos ritmos históricos que coexisten y se solapan inclusive dentro de los espacios nacionales (POLAR, 1991, p. 6).
El fenómeno en mención se percibe, también, en otros países latinoamericanos $\mathrm{y}$, de manera atomizada, a lo largo $\mathrm{y}$ ancho de sus territorios. A partir de esta primera categoría sociocultural, se desprende otra no menos relevante: el principio de alteridad. Éste, por utópico que suene, intenta reconocer y otorgar "estatuto de ciudadanía" a quienes, dentro de un espacio vital, no comparten cultura, expectativas, biotipo, identidad, etc. Sin embargo, tal categoría no deja de ser conflictiva en sí, si tenemos en cuenta, como bien remarca Zygmunt Bauman (2005), la naturaleza cambiante y líquida, especialmente en estos últimos tiempos, de nuestros marcos identitarios referenciales. Pese a ello, la alteridad sigue siendo un asunto vigente que cobra características disolutivas notorias y que, además, puede entenderse como: "...un concepto filosófico, que actualmente se encuentra en el centro de la reflexión sobre los fenómenos interculturales" (MACAIRE, 2008, p. 30). 
Teniendo en cuenta En ella el narrador-testigo las nociones expuestas, habla sobre su vida presente y centraremos nuestra mirada su estadía en Florencia, Italia. en El hablador de Mario Vargas Llosa. La novela se caracteriza por presentar dos voces que se entrelazan y alternan. Estas nos relatan una historia peculiar desde dos perspectivas opuestas (pero complementarias). Por un lado, está la voz del narrador-testigo que recuerda a Raúl Zuratas, colega de universidady amigo de juventud, apodado "Mascarita", quien siente fascinación por las culturas amazónicas nativas. Por otro, la de un contador nómade de historias o sea la de un "hablador" o memoria viviente de los machiguengas. Esta última voz, nos presenta, a través de un lenguaje arcaico y a la vez poético, los mitos originarios de esa etnia y la función que, dentro de esas narrativas, cumplen los habladores.

La obra se estructura en tres secciones. Estas, empero, no siguen un estricto orden lineal. Una primera sirve de marco diegético y referencial.

Una segunda, se remonta en el tiempo y narra aspectos de la juventud del narrador-testigo como su paso por los claustros de la Universidad de San Marcos y su amistad con Saúl Zuratas. A través de esa relación se estructuran parlamentos y situaciones discursivas que enfrentan el orden moderno, occidental, urbano, con lo "arcaico", indígena-amazónico y natural; es decir, un campo dialógico donde los signos que colisionan y se entrelazan refuerzan la tendencia discursiva dispar y quebrada de la sociedad peruana en su conjunto. Finalmente, una tercera sección, guiada por la segunda voz narradora, recopila las aventuras del hablador, de Tasurinchi (dios creador machiguenga) y las luchas de este último dios (emparentado en algunos puntos con el Cristo de los Evangelios) con las divinidades lideradas por el cruel Kientibakori. La segunda voz, de este modo, articula su relato con historias ancestrales, 
con leyendas y rituales ambientados en lo profundo de la selva, en lugares ocultos y aún "no contaminados" por el avance de la civilización occidental.

Dentro de los temas más importantes que organizan la historia, tenemos: el conflicto modernización/ tradición. Éste se organiza, principalmente, en torno a las diferencias habidas entre el narradortestigo (promotor de la "modernización") y Saúl (crítico feroz de la "homogenización modernizadora"). Por otro lado, la pervivencia de la cultura indígena a través del ejercicio de la oralidad y del mito como elemento estructurador de sus sociedades ${ }^{2}$. Todo ello genera una serie de binarismos: oralidad vs. escritura, verdad vs. ficción, comunidad vs. nación, tradición vs. modernidad, economía de subsistencia vs. economía capitalista, etc.

La novela es, pues, la puesta en relieve de dos puntos de vista antagónicos cuyos portadores,

colegas y amigos durante parte de sus vidas universitarias, por razones obvias, comenzarían a distanciarse. Dos visiones enfrentadas sobre un mismo "candente" objeto: el Perú amazónico. Uno, el del narradortestigo, crítico severo del atraso y arcaísmo de los indígenas amazónicos, especialmente de los machiguengas de las selvas de Cusco y Madre de Dios y otro el de Zurata, joven peruano de origen judío que defiende la causa indígena y su no "contaminación".

En 1956 (Mascarita)
estudiaba Etnología al
mismo tiempo que Derecho
y había estado varias veces
en la selva. Sentía esa
fascinación de embrujado
por los hombres del bosque
y la naturaleza sin hollar,
por las culturas primitivas,
minúsculas, desperdigadas
en las colinas montuosas de
la ceja de montaña y la llanura
de la Amazonía? Ardía ya en
él ese fuego solidario brotado
oscuramente de lo más
hondo de su personalidad
por esos compatriotas
nuestros que desde tempos
inmemoriales vivían allá,
acosados y lastimados, entre

2 Nos encontramos aquí ante un conflicto medular, suscitado a partir de la noción de "ciudad letrada", categoría propuesta por Ángel Rama en el libro del mismo nombre (1989). 
los anchos y lentos ríos, con taparrabos y tatuajes, adorando los espíritus del árbol, la serpiente, la nube y el relámpago (LLOSA, 1995, p. 6).

Zuratas, curiosamente, tiene un aspecto llamativo: la mitad de su rostro presenta un angioma, una mancha rojovinosa que lo transforma en un "monstruo", en un marginal, en un "otro" rechazado por la gente "normal" de la ciudad y que busca refugio en aquellos "otros" (tampoco "normales") que viven "desnudos y en la "edad de piedra" en la Amazonía sur-oriental del Perú. He allí la razón de ser de su apodo.

$\begin{array}{ccr}\text { Tras } & \text { abandonar } & \text { los } \\ \text { claustros } & \text { universitarios } & y\end{array}$ distanciarse de Lima, Zuratas termina convirtiéndose en el nuevo "hablador" de los machiguengas es decir, en el portador de la tradición mítica y oral de esa comunidad. A diferencia de "Mascarita", el narrador-testigo mantiene una considerable distancia con el pueblo machiguenga. Éste, como el autor biológico, es un escritor cosmopolita que se encuentra de visita en
Italia, en una galería donde se exponen las fotografías de un artista famoso, muerto poco después de recorrer con su cámara algunos parajes de la Amazonía peruana. Allí, de casualidad, encuentra unas fotos que le resultan conocidas pues él también recorrió esos remotos lugares $\mathrm{y}$, sobretodo, porque encuentra, confundido entre los indios, a su antiguo camarada Saúl Zuratas. De este modo, a través del ejercicio de la memoria, se establecen las primeras caracterizaciones del espacio amazónico y de los nativos, como una otredad "maculada" que debe ocultarse o desaparecer.

El artista se había dispuesto a describir, 'sin demagogias ni esteticismo' la existencia cotidiana de una tribu que, hasta hacía pocos años, vivía casi sin contacto con la civilización,... El nombre de la tribu estaba castellanizado sin errores: los machiguengas. Las fotos mostraban con elocuencia cuán pocos eran en esa inmensidad de cielo, agua y vegetación..., su vida frágil y frugal, su aislamiento, su arcaísmo, su indefención. Era verdad: sin demagogia ni esteticismo. Y esto fue una certidumbre cuando, en otra 
de las fotografías, vi, con las misma barriguita hinchada y los mismos ojos vivos que conservaba en mi recuerdo, al niño de boca y nariz comidas por la uta. Mostraba a la cámara, con la misma inocencia y naturalidad con que nos lo había mostrado a nosotros, ese hueco con colmillos, paladar y amígdalas que le daba un aire de fiera misteriosa (LLOSA, 1995, pp. 4-5).

Il signore Gabriele Malfatii é morto? Muerto? Sí. De unas fiebres. Un virus contraído en aquellas selvas (...) El pobre! Era un fotógrafo de modas, había trabajado para Vogue, para Uomo, revistas así, fotografiando modelos, muebles, joyas, vestidos. Se había pasado la vida soñando con hacer algo distinto, más personal, como este viaje a la Amazonía. Y cuando al fin pudo hacerlo y le iban a publicar un libro con su trabajo, se moría! (...) (LLOSA, 1995, p. 5).

\section{La Amazonía aparece} como un espacio peligroso que engulle y mata. Gabriel Malafatti, el famoso fotógrafo, fue una víctima de aquella región indómita. Al mismo tiempo, la misma constitución de la sociedad machiguenga, es decir su organización comunitaria, es para el narrador-testigo un impedimento de progreso y perdurabilidad y un obstáculo para la elaboración de taxonomías etnológicas.

Aunque se trataba de la misma tribu, los machiguengas cuyo número se calculaba, a ciegas, entre cuatro y cinco mil- estaban desigualmente vinculados con el resto del Perú y entre sí mismos. Era un pueblo fracturado. (...). El otro sector de la comunidad - pero ¿se podía hablar, en estas condiciones, de una comunidad? -, diseminado en el extensísimo territorio de las hoyas de los ríos Urubamba y Madre de Dios, se mantenía aún, a fines de los años cincuenta, celosamente aislado y se resistía a todo tipo de comunicación con los blancos. (...) Pero ni siquiera ese sector era homogéneo. Había, entre los machiguengas más primitivos, un pequeño grupo o fracción aún más arcaico, enemistado con el resto. Los llamados "kogapakori". (...). Casi no habían sido estudiados. Salvo un pequeño libro, publicado en 1943 por un dominico, el Padre Vicente de Cenitagoya, y algunos artículos de otros misioneros sobre su folklore y su lengua, aparecidos en las revistas de la Orden, no existía un trabajo etnográfico serio sobre ellos. Pertenecían a la familia arawak y se confundían 
algo con los campas de los ríos Ene y Perené y el Gran Pajonal, pues sus idiomas tenían raíces semejantes. $\mathrm{Su}$ origen era un misterio total; su identidad, borrosa (LLOSA, 1995, pp. 32-33).

Ante las propuestas $\mathrm{y}$ políticas predominantes de asimilación, surge con mayor energía la voz de "Mascarita". Éste, dirigiría sus críticas a todo una multitud de funcionarios nacionales y extranjeros, lingüistas y religiosos cuya misión esla de borrar todahuella de las culturas amazónicas. Para este personaje, la labor de los evangelizadores protestantes norteamericanos (quienes, gracias a su capacidad económica, desplazaran a los sacerdotes católicos de las misiones) era aún más perniciosa:

- Ellos son los peores de todos, tus apostólicos lingüistas. Se incrustan en las tribus para destruirlas desde adentro, igualito que los piques. En su espíritu, en sus creencias, en su subconsciencia, en las raíces de su modo de ser. Los otros les quitan el espacio vital y los explotan o los empujan más adentro. En el peor de los casos, los matan físicamente. Tus lingüistas son más refinados, los quieren matar de otro modo. ¡Traduciendo la Biblia al machiguenga, qué te parece! (LLOSA 1994, p. 37).

Ellos también les quieren robar el alma, por supuesto. Pero, a los misioneros se los está tragando la selva, como al Arturo Cova de La vorágine. ¿No los has visto, en tu viaje?... Viven en un desamparo tal que ya no están en condiciones de evangelizar a nadie, felizmente... Los lingüistas eran algo muy diferente. Tenían, detrás de ellos, un poder económico y una maquinaria eficientísima que les permitiría tal vez implantar su progreso, su religión, sus valores, su cultura. ¡Aprender las lenguas aborígenes, vaya estafa! ¿Para qué? ¿Para hacer de los indios amazónicos buenos occidentales, buenos hombres modernos, buenos capitalistas, buenos cristianos reformados? $\mathrm{Ni}$ siquiera eso. Sólo para borrar del mapa sus culturas, sus dioses, sus instituciones y adulterarles hasta sus sueños. Como habían hecho con los pieles rojas y los otros, allá en su país. ¿Eso quería para nuestros compatriotas de la selva?... ¿Que se volvieran sirvientes y lustrabotas de los viracochas? (LLOSA, 1995, pp. 38-39).

Para Saúl, a diferencia del narrador-testigo, el indio 
amazónico sí supo sobrevivir a lo largo de los siglos y, pese a los crímenes perpetrados en su contra, lograron mantener parte de su hábitat y sus costumbres milenarias. Tal postura puede vincularse a la de otros intelectuales de "carne y hueso" quienes, desde los distintos países de la Panamazonía, toman partido por la cuestión indígena y su entorno natural.

Hasta ahora nadie lo había conseguido, pero podía ser que esta vez los lingüistas se salieran con la suya. En cuatrocientos, quinientos años de intentos, todos los otros habían fracasado. Nunca habían podido someter a esas tribus pequeñitas que despreciaban. Yo lo había leído en las Crónicas que fichaba donde Porras Barrenechea,... Lo que les pasó a los Incas, cada vez que mandaron ejércitos al Antisuyo. A Túpac Yupanqui, sobre todo, ¿no lo había leído? Cómo sus guerreros se desvanecieron en la selva, cómo los Antis se les escurrieron entre los dedos. No habían sometido a uno solo y, despechados, los civilizados cusqueños se pusieron entonces a menospreciarlos. Por eso inventaron todos esos vocablos peyorativos en quechua contra los indios salvajes, depravados. Y, sin embargo, ¿qué le ocurrió al Tahuantinsuyo cuando debió hacer frente a una civilización más poderosa? Los bárbaros del Antisuyo, al menos, seguían siendo lo que eran, ¿no? ¿Y acaso los españoles habían tenido más éxito que los Incas? ¿No habían sido todas sus «entradas» un fracaso absoluto? Los mataban cuando podían echarles la mano encima, pero ocurrió rara vez. Los miles de soldados, aventureros, fugitivos, misioneros que bajaron al Oriente entre 1500 y 1800 ipudieron acaso incorporar una sola tribu a la muy ilustre civilización cristiana y occidental? Todo eso ¿no significaba nada para mí? - Dime, más bien, qué significa para ti, Mascarita - le contesté. Que esas culturas deben ser respetadas - dijo,...Y la única manera de respetarlas es no acercarse a ellas. No tocarlas. Nuestra cultura es demasiado fuerte, demasiado agresiva. Lo que toca, lo devora. Hay que dejarlas en paz. ... ¿ $\mathrm{O}$ sea que tenemos que resucitar el Tahuantinsuyo? ¿También los sacrificios humanos, los quipus, la trepanación de cráneos con cuchillos de piedra? Es gracioso que el último indigenista del Perú sea un judío, Mascarita. Bueno, un judío está mejor preparado que otros para defender el derecho de las 
culturas minoritarias a existir - me repuso -. Después de todo, como dice mi viejo, el problema de los boras, de los shapras, de los piros, es nuestro problema hace tres mil años (LLOSA, 1995, p. 39).

Según Nelson González Ortega (2011), estamos ante un relato de vocación etnográfica. Un relato en el que convergen el quehacer del etnólogo con el oficio del novelista; un texto donde se funden (y confunden) el punto de vista literario con la óptica antropológica. El autor da vida a un novelista-etnólogo que estudia y expone ciertas facetas de la vida de los machiguengas. Para ello, se vale de algunos métodos de trabajo comunes a la etnografía (recopilación, evaluación y estructuración de datos) y a la creación literaria (adopción de dos narradores con sus respectivos puntos de vista, relación de los hechos a manera de una narración y no tanto como un informe académico y una perspectiva antropológica dominante ${ }^{3}$ ). En otras palabras, la creación de un procedimiento a través del cual se elabora un reporte etnográfico y se lo adapta a los moldes de la novela. El hablador, por tanto, deconstruye el discurso antropológico a través de la "literaturización" de sus objetivos, técnicas y métodos de trabajo y, del mismo modo, de la autoridad de dicho discurso que, desde mediados del siglo pasado, enfatiza González Ortega (2011), impregna la ficción literaria latinoamericana.

De este modo, notamos en el análisis una disputa ideológica, un contrapunto dado a nivel discursivo-lingüístico y que, siguiendo a Raymond Williams (2000, p.134), se traduce en el enfrentamiento de dos voces o posturas culturales distintas: una hegemónica y otra contrahegemónica. Una que pretende ahogar toda manifestación distinta a la del establishment y otra que no sólo aboga por esa diversidad sino que solicita se respete a esos individuos y sus espacios. Esto, como se observó, consolida un espacio

3 Según la narratología de Gerard Genette, la perspectiva, tradicionalmente llamada "punto de vista" o focalización se refiere a la posición del narrador con respecto a los 
discursivo confrontacional, transculturales articulados signado por una tensión por voces no indígenas) y simbólica permanente de los soportes orales del cuyo sentido conflictivo se remonta a los primeros años de la conquista y arraiga aún en la actualidad. Todo esto refleja las rupturas internas existentes en la nación-estado peruano, debido a la presencia problemática y no equitativa de universos culturales heterogéneos. En este contexto quebrado, refiere Luis Hernán Castañeda (2011), aparece la figura "especular" del escritor latinoamericano moderno; hijo nostálgico y apologético de una "ciudad letrada", construida, paradójicamente, como contracara de la figura de los narradores orales.

Como una narrativa elaborada desde coordenadas urbanas, letradas y cosmopolitas, El hablador problematiza las posibilidades de supervivencia y renovación del indigenismo (como un conjunto de textos propio universo indígena. Esta situación se evidencia, aún más, gracias a los aportes de Ángel Rama y su ensayo $L a$ transculturación narrativa en América Latina. Para Rama, la cultura latinoamericana es dueña de una energía transformadora que opera a partir de dos vectores culturales enfrentados: la tradición milenaria indoamericana y los aportes estético-ideológicos de la cultura europea (2008, p.66). De este modo, los narradores de la novela, ponen en evidencia un doble pasaje cultural, una transculturación de ida y vuelta: la de los machiguengas que lentamente se asimilan a los cánones hegemónicos y la de Zuratas, hombre urbano (aunque marginal) que deja atrás su antigua vida para mantener viva la tradición oral machiguenga.

Estamos, pues, ante una

personajes y las acciones a lo largo de la diégesis. En el hablador, la perspectiva narratológica dominante que es la del narrador-testigo y la del hablador mismo, es de naturaleza antropológica. Sin embargo, debe tenerse en cuenta que esta última funde sus límites con la narrativa de carácter literario. Cf. Figuras III, 1989, p. 241. 
doble materia transcultural: una interna, tradicional y autóctona que es absorbida por categorías epistémicas externas, con las cuales busca reconocimiento y legitimación. $Y$ otra distinta, heterodoxa, que parte de la propuesta ramiana pero la supera. Esta, presenta significados internos que toman y subordinan a ellos formas externas. En otras palabras, significados míticos propios (e inalienables) que absorben códigos occidentales con el fin de resistir. En este punto, "Mascarita" aparece como un narrador oral que reescribe, en lengua vernácula, todo un cosmos de referencias culturales. Tales referencias son captadas en su versión distorsionada del español $\mathrm{y}$ son vertidas, igualmente, en las matrices lingüísticas, narrativas y epistemológicas de un auditorio ideal. En este punto (y desde una perspectiva invertida), la lengua de dominio, o sea el español, se constituye en lengua marginal. En la segunda narración, como contracara de la primera, los mitos modernizadores y globalizadores se subordinan a las estructuras míticas machiguengas.

La novela deviene no sólo en la problematización de la vigencia cultural indígena sino, también, del mito del escritor latinoamericano moderno que, durante gran parte del siglo $\mathrm{XX}$, se fundió con la figura del literato comprometido o artesano capaz de darle voz al otro o, al menos, hablar (y sin su permiso) en su nombre. Muchos de estos escritores (como es el caso del mismo Vargas Llosa ${ }^{4}$ ), entienden ser superiores a los narradores indígenas. No obstante, en El hablador, el narrador machiguenga demuestra una conexión poderosa con su comunidad, con su entorno natural y una gran influencia sobre sus receptores (situación, que en muchos casos, el escritor actual siente haber perdido).

"Mascarita" aconseja a su grupo étnico adoptivo, como método de resistencia,

4 Al respecto, téngase en cuenta el ensayo de este mismo escritor: La utopía arcaica. José María y las ficciones del indigenismo. 
la práctica del nomadismo y evitar, así, todo contacto con las redes del estado-nación. Para Castañeda (2011), gracias a este recurso, hablador $\mathrm{y}$ comunidad se funden en un único cuerpo, en una sola entidad con características de viajero antinacional que huye hacia las periferias, hacia los bordes, lejos de construcciones artificiosas impuestas como las ideas de estado moderno y civilización occidental. No obstante, se debe resaltar que "Mascarita" no es un machiguenga auténtico. $\mathrm{Su}$ historia es la invención de un narrador que reconstruye episodios dispersos a partir de la invención, la memoria y la nostalgia; una forma de reflexionar sobre el rol del escritor latinoamericano contemporáneo en tiempos, en palabras de Luis Castañeda (2011), de reacciones antiutópicas, prácticas y menos románticas; una crítica al rol del escritor comprometido, al novelista que pergeña metarelatos interpretativos de la realidad social y propone soluciones ilusorias a los problemas del continente.

Llama la atención, pues, lo sugerido en torno a la pérdida de influencia del escritor, del deterioro de su compromiso político. Por otro lado, la exaltación de un narrador oral que, dentro de su comunidad, tiene mayor credibilidad $\mathrm{y}$ aceptación, aunque no deje de ser una suerte de espectro que se difumina ante el avance de los frentes urbanos, letrados y modernizadores. La transculturación heterodoxa de "Mascarita", lastimosamente, sólo surte efecto en la ficción vargallosiana. Ella discurre como resto, vestigio o como el eco fantasmal de un modo de comprender el oficio de escribir que forma parte del pasado y que si hoy carece de productividad, al menos conserva el encanto sutil de una reliquia.

Puede subrayarse, finalmente, lo dicho por Luis Castañeda sobre esta novela (2011): que es un relato amazónico kafkiano en clave pesimista donde el escritor intelectualizado, como los 
narradores

machiguengas, tienden a la extinción. La comparación es bastante ilustrativa. La cultura letrada de antaño se equipara a las narraciones orales indígenas, pues ambas andan por un mismo derrotero: el de la desaparición.

\section{Referencias}

BAUMAN, Z. Identidade. Entrevista com Benedetto Vecchi. Tradução de Carlos Alberto Medeiros. Rio de Janeiro: Jorge Zahar Editor, 2005.

CASTAÑEDA, L. H. “'El hablador' (1987) de Mario Vargas Llosa: Una metamorfosis transcultural". (blog). Disponible en: https://goo. gl/MD9J8G. Consultado el 15 de setiembre de 2011.

FANON, F.Oscondenados daterra. Tradução de Enilce Albergaria Rocha e Lucy Magalhães. Juiz de Fora: Editora UFJF, 2005.

GENETTE, G. Figuras III. Traducción al español de Carlos Manzano. Madrid. Edit. Lumen, 1989. Disponible en: https://goo. gl/gCTbJk. Consultado el 12 de setiembre de 2017.

LLOSA, M. V. El Hablador. Barcelona: Seix Barral, 1995. Disponible en: https://goo. gl/9pgrD3. Acceso el 23 de mayo de 2017.

LLOSA, M. V. La utopía arcaica. José María Arguedas y las ficciones del indigenismo.
México: Fondo de Cultura Económica, 1996.

MACAIRE, M. C. "Reflexiones sociocríticas sobre la alteridad. El otro modelo hegemónico y el tercer interpretante", En: Káñina, Revista Artes y Letras, Universidad de Costa Rica, v. XXXII (1), 2008, pp. 29-38. Disponible en: https:// goo.gl/wmwdG1. Consultado el 28 de agosto de 2017. MIGNOLO, W. La idea de América Latina. La herida colonial y la opción decolonial. Tradução ao espanhol de Silvia Jawerbaum e Julieta Barba. Barcelona: Gedisa, 2005. Disponível en: https:// goo.gl/onwUFt. Acesso em 15 de agosto de 2017.

ORTEGA, N. G. "Fronteras del relato: El hablador de Mario Vargas Llosa, novela o reporte etnográfico?" Revista Mitologías hoy, Universitat Autônoma de Barcelona, n.3, otoño de 2011, pp. 35-45. Disponible en: https://goo. gl/sQd98D. Consultado el 12 de setiembre de 2017.

POLAR, A. C. Escribir en el aire. Ensayos sobre la heterogeneidad sociocultural en las literaturas andinas. Lima: Editorial Horizonte, 1991.

RAMA, A. La ciudad letrada. Montevideo: $\quad$ ARCA, 1998. Disponível en: https://goo.gl/ pvVoQB. Acesso 12 de agosto de 2017.

RAMA, A. Transculturación narrativa en América Latina. Buenos Aires: Ediciones El 
Andariego, 2008. Disponible Literatura. Tradução ao espanhol en: https://goo.gl/qYUqW1. de Pablo di Masso. Barcelona:

Consultado el 10 de setiembre de Ediciones Península, 2000. 2017

Data de recebimento: 01/12/2017

WILLIAMS, R. Marxismo y Data de aceite: $26 / 12 / 2017$ 